\title{
De Greimas a Jacques Geninasca. Por uma semiótica da fala
}

\author{
Michael Schulz' \\ https://orcid.org/0000-0001-6691-2537 \\ I - Metadesign \\ Genebra, Suíça
}

Resumo: Este artigo mostra como, embasado em princípios epistemológicos partilhados, Greimas e Geninasca situaram suas pesquisas a níveis de pertinência diferentes e alimentaram dois projetos semióticos distintos, um voltado para a "língua", outro para a "fala". Greimas coloca a coerência e a inteligibilidade dos discursos sob a dependência de uma - e de somente uma - estrutura da significação, ao mesmo tempo elementar e universal. Essa estrutura, da qual o quadrado semiótico é o modelo, seria anterior e independente da atividade enunciativa. Na economia global da teoria semiótica de Greimas ela faz parte das estruturas profundas, situadas na "língua". Geninasca, por seu lado, procura analisar as estratégias de coerência que permitem instaurar os textos em "discursos", isto é, em objetos semióticos. Fazendo isso, ele coloca a emergência da significação no final de uma atividade atribuível à instância enunciativa. Ao privilegiar o nível discursivo, ele define a semiótica como uma teoria das "condições para a instauração dos discursos", o que equivale a orientá-la para a "fala" e abre um conjunto de questões novas. A teoria semiótica se define desde então em relação a um novo conjunto de questões. Em particular, ao problema das conversões entre os níveis de profundidade previstos pelo percurso gerativo da significação de Greimas, Geninasca substitui a questão da integração de uma pluralidade de linguagens, de apreensões do sentido e de racionalidades.

Palavras-chave: teoria semiótica; discurso; racionalidade; Greimas; Geninasca.

Abstract: From Greimas to J. Geninasca: On the Semiotics of Discourse - This article concentrates on demonstrating how Greimas and Geninasca, while sharing the same epistemological principles, have positioned their respective research at different levels and pioneered two distinct semiotic projects, one orientated towards the langue, the other towards the parole, as defined by F. de Saussure. For Greimas indeed, the coherence and intelligibility of texts depends on one - and only one - elementary and universal structure of signification. This structure, the model of which is the semiotic square, is supposed to be prior to, and independent of any enunciative activity. Within the general framework of Greimas' semiotic 
theory, it lies in the deep structures, located in the langue. Geninasca's approach is different. He aims at conceptualising different strategies of coherence allowing to construct texts as 'discourses', that is, as semiotic objects. In doing so, he approaches the emergence of signification as the result of an activity attributable to a subject of enunciation. Favouring the surface structures, he assigns the semiotic theory the task to describe the "prerequisites for building discourses", which is a way to focus on what Saussure calls parole. In this light, the semiotic theory concentrates on a different series of questions. Rather than tackling the problem of the conversion between different levels of depth, constitutive of Greimas' generative path of signification, it addresses the question of the integration, by a subject of enunciation, of multiple languages, rationalities and ways of creating sense and meaning.

Keywords: semiotic theory; discourse; rationality; Greimas; Geninasca.

Claro que, com a entrada no discursivo, tudo muda e os problemas não mais se referem a níveis nem a conversões. É outra história. Sobre isso, eu não disse nada, ou quase, exceto, talvez, estimular as pessoas a pesquisar, a entender. Carta de A.J. Greimas a J. Geninasca, s.d. [agosto de 1988]'

O primeiro encontro entre Greimas e Geninasca ocorreu na Itália, em Urbino, durante o verão de 1968. A história registrada em um texto de Geninasca em homenagem a Greimas diz que isso aconteceu sob o signo da ordenação cavalheiresca: "Você pode se considerar membro da Escola de Paris" (GENINASCA, 1993, p. 25). Esse foi o enunciado proferido pelo mestre com relação ao pesquisador suíço após tê-lo ouvido expor suas "Notas para uma análise estrutural do primeiro cântico da Divina Comédia" (GENINASCA, 1969). Essa reunião marcou o começo de uma "amizade" que duraria os vinte e cinco primeiros anos da teoria semiótica a que Greimas vinculou seu nome (GENINASCA, 1993, p. 26). Concordando sobre alguns princípios epistemológicos fundamentais, Greimas e Geninasca ligaram-se por um contrato fiduciário nunca questionado apesar de discordâncias declaradas desde o começo dos anos 70 em vários pontos essenciais da teoria. De temperamento fortemente livre e independente, Geninasca, por outro lado, muito rapidamente afastou-se da "Escola de Paris", esse círculo do mestre que ele considerava pecar pelo "espírito de capelinha" e uma tendência marcada de reduzir o pensamento de Greimas a uma espécie de doxa semiótica (LANDOWSKI, 2017, pp. 159-163).

\section{Uma diferença de perspectiva em um contexto de paixão comum}

Situados na tradição de estudos de Saussure, Hjelmlev, Benveniste e Lévi-Strauss, Greimas e Geninasca compartilharam a concepção comum de uma teoria semiótica cujo objetivo é a modelagem dos mecanismos que governam a produção e apreensão da significação. Inscrevendo-se em oposição a uma semiótica do signo-referência de inspiração peirciana, os dois pesquisadores defendiam uma semiótica dos conjuntos

1 As cartas trocadas por Greimas e Geninasca estão na Bibliothèque de la Ville et de l'Université de Neuchâtel (Fonds Jacques Geninasca). 
significantes que subordina a construção da significação a uma análise que está ao mesmo tempo aquém dos signos, no nível de redes relacionais de diferenças pertinentes que estes articulam, e além deles, no nível dos enunciados discursivos e de sua organização. A antecedência pertence assim ao conceito de relação, que constitui o centro dos princípios epistemológicos fundamentais ao qual Greimas e Geninasca davam a maior importância. Essa prioridade concedida à relação explica também sua exigência comum de fundar uma teoria num conjunto consistente de hipóteses e conceitos interdefinidos, assim como a convicção de ambos que em ciência só há fatos em virtude de uma teoria geral e só há teoria em função do campo empírico que a própria teoria instaura.

Defensores da discussão franca, tanto Greimas como Geninasca gostavam do confronto de ideias. Um e o outro tinha a coragem da invenção, que lhes permitiu sair de caminhos já trilhados e explorar novos modos de enriquecer a teoria. Animados pela mesma paixão pela causa semiótica, suas respectivas pesquisas alimentaram, contudo, duas semióticas distintas tanto nos conceitos teóricos que mobilizaram como nos campos empíricos que se dedicaram a explorar. Uma comparação entre a formulação da primeira das "condições gerais de uma teoria semiótica" tal como a define o Dicionário de Semiótica e sua reformulação por Geninasca, que, referindo-se expressamente a ela, a parafraseia no final do prefácio de La Parole littéraire permitirá por um lado determinar até que ponto a semiótica de Geninasca nasce de um diálogo crítico com a semiótica greimasiana e, por outro, avaliar a diferença de perspectiva entre as reflexões dos dois semioticistas.

Por uma conveniência de leitura, eis a formulação do Dicionário:

A teoria semiótica deve apresentar-se inicialmente como o que ela é, ou seja, como uma teoria da significação. Sua primeira preocupação será, pois, explicitar, sob forma de construção conceptual, as condições da apreensão e da produção do sentido (GREIMAS; COURTÉS, 1987, p. 415).

Geninasca a reformula assim em La Parole littéraire:

\begin{abstract}
A teoria semiótica deve apresentar-se, em primeiro lugar, tal como é, isto é, como uma teoria das condições da instauração dos discursos. Sua primeira preocupação será por isso explicitar, na forma de uma construção conceitual, as estratégias de coerência que, a partir de objetos textuais naturais ou produzidos, possam instalar textos instauráveis como objetos semióticos (GENINASCA, 1997, p. 16)²
\end{abstract}

O que toma forma aqui, na base de uma equivalência parafrástica, são duas maneiras de pensar o objeto e a tarefa da teoria semiótica. Recorrendo à dicotomia sentido/ significação, Greimas atribui à teoria semiótica a tarefa de conceituar a transformação do sentido em significação. Definindo esta última segundo a tradição saussuriana e

2 "La théorie sémiotique doit se présenter, d'abord, pour ce qu'elle est, c'est-à-dire comme une théorie des conditions d'instauration des discours. Son souci premier sera donc d'expliciter, sous forme d'une construction conceptuelle, les stratégies de cohérence qui, à partir d'objets textuels naturels ou produits, soient en mesure d'installer des textes instaurables comme objets sémiotiques." Grifos do autor. 
hjelmsleviana como produção e/ou apreensão de diferenças pertinentes, ele encarrega a teoria de construir o conjunto de conceitos necessários "para estabelecer a definição da estrutura elementar da significação" (GENINASCA, 1997, p. 16). Na economia global da teoria semiótica, à qual Greimas dá, como se sabe, uma forma gerativa que permite conceber a construção de objetos semióticos segundo o seu modo de produção, a estrutura elementar da significação é parte de estruturas profundas, localizadas, diríamos, "na língua [langue]". As "condições da apreensão e da produção do sentido" que a semiótica greimasiana visa a conceituar na forma de uma "teoria da significação" são pensadas como restrições estruturais, prévias a e independentes de sua mobilização por uma instância de enunciação. Geninasca, por sua vez, busca conceituar "estratégias de coerência" que permitam instaurar textos em "discurso", isto é, como objetos semióticos. Assim agindo, situa a emergência da significação ao final de uma atividade atribuível a uma instância enunciativa. Privilegiando assim o nível discursivo, ele define a semiótica como uma teoria das "condições de instauração dos discursos", o que equivale a orientála rumo a "fala" no sentido de Benveniste.

Enquanto Greimas permaneceu vinculado, na definição da teoria semiótica, à exigência de generalidade e universalidade herdada da grande tradição comparatista da linguística, Geninasca pedia à semiótica que fosse uma ciência do geral e uma ciência do particular. A ambição da semiótica de Geninasca é elaborar uma teoria do discurso que permita ao mesmo tempo instaurar uma tipologia geral dos discursos e dar conta da especificidade de discursos singulares, notadamente daqueles que são parte do conjunto dos discursos literários, e de modo mais geral, estéticos. Desde sua Analyse structurale des Chimères de Nerval, publicado em 1971, Geninasca, de fato, multiplicou as microanálises de textos literários com o duplo objetivo de expor a especificidade do mundo do discurso de um autor dado, e de "formalizar os problemas ligados à análise dos textos poéticos" (GENINASCA, 1971, p. 9), pretendendo contribuir para a construção de uma "gramática do discurso poético" (GENINASCA, 1971, texto aba).

Empenhados um e outro na busca do sentido, Greimas e Geninasca se sobressaíram na análise das mais diversas práticas discursivas - textos literários, quadros, gestos, mitos ou receitas de cozinha - ao mesmo tempo situando suas pesquisas, em última análise, em níveis de pertinência diferentes. Linguista de formação, o Greimas semioticista investigava as profundezas das estruturas fundamentais com a intenção de contribuir para a compreensão do homem como ser de linguagem e ser social. Pintor por vocação, Geninasca explorou a espessura das estruturas da superfície, tentando entender, antes de mais nada, a visão de mundo e do humano que os discursos estéticos oferecem.

\section{Significação e estratégias de coerência}

A prática de análise de Geninasca muitas vezes incidia, como se sabe, sobre textos, literários e imagéticos, notórios por seu hermetismo. Diante das especulações de alguns 
críticos sobre a ilegibilidade da poesia e da arte modernas, Geninasca fez uma aposta na inteligibilidade de obras de Reverdy, Char, Saint-John Perse ou Magritte. Em La Parole littéraire, no início do capítulo dedicado ao poema "Lutteurs" de René Char, ele lembra que "'dizer o indizível' - supondo, claro, que essa seja a vocação da poesia moderna é, ainda e sempre, dizer, explorar, por conseguinte, submetendo-se a elas, as estratégias de coerência que condicionam a produção e a expressão de textos instauráveis como discursos" (RUPRECHT, 1997, p. 163). E no capítulo dedicado ao poema "Blanc et Noir" [Branco e Preto], de Pierre Reverdy, ele escreve:

Longe de ser uma propriedade dos próprios textos, o 'hermetismo" da poesia moderna se revela como o reconhecimento involuntário de uma incompetência de leitura: a incapacidade de adotar com relação à língua ou ao mundo (ao modo de presença de suas figuras na obra), uma atitude correspondente às operações e recursos que governam a produção do poema como todo de significação. O 'hermetismo' em si é apenas um efeito de leitura ligado à ignorância do público ou à inadequação dos modelos que se busca a aplicar aos textos poéticos (RUPRECHT, 1997, p. 235).

Subordinando a legibilidade de um texto, verbal ou visual, à atualização de uma estratégia da coerência adequada às propriedades discursivas do texto, Geninasca concebe a significação em termos de operações enunciativas ao mesmo tempo que postula a existência de uma multiplicidade de estratégias de coerência, cada uma das quais atende às condições de objetividade e subjetividade. A atualização das operações que compõem uma estratégia de coerência é ao mesmo tempo condicionada pelas virtualidades discursivas de um texto dado, e atribuível a uma instância de enunciação em busca de inteligibilidade e sentido. Em outras palavras, nem toda estratégia de coerência é aplicável a todo texto.

Para Geninasca, a coerência e, em consequência, a significação de um enunciado discursivo, verbal ou visual, não é dada, mas depende inteiramente das operações que a instauram. Antes de ser assumida por uma instância de enunciação, o enunciado discursivo ainda é apenas a promessa de um objeto significante. É um objeto textual no qual cada estratégia de coerência atualiza algumas propriedades discursivas a fim de informá-lo como um texto consistente e construí-lo como um todo de significação. Nessa perspectiva, esse enunciado discursivo não é o lugar de inscrição de uma mensagem invariável ou de um sentido préestabelecido que se trataria de revelar, mas se mostra como um campo de operações virtuais que se presta à atualização de uma ou várias estratégias de coerência, fazendo cada uma ser uma significação que coincide com a atividade enunciativa que a produz.

Esclareçamos que a possibilidade de empregar várias estratégias de coerência sobre o mesmo texto é alheia à tese da "leitura infinita". Ela também não corresponde à multiplicidade dos protocolos de leitura induzidos por estilos de leitura distintos (leitura linear e exaustiva, leitura em diagonal, busca de informações, leitura por prazer etc). Leituras múltiplas e protocolos de leitura remetem à quantidade e variedade de exercícios 
de leitura possíveis, enquanto o conceito de multiplicidade de estratégias de coerência é um produto da possibilidade de conceituar modos diferentes de instauração da coerência, ou seja, competências discursivas diferentes que definem, cada uma, condições de legibilidade diferentes.

\section{Racionalidades e apreensões do sentido}

Sendo o sentimento de coerência função da possibilidade de pensar o pertencimento de partes a um todo, será possível definir um modo de instauração da coerência mediante o tipo de relação que instala entre as grandezas de um nível de pertinência ou apreensão dado. Geninasca denomina racionalidade todo modo de instauração da coerência, quer dizer, "qualquer modo de assegurar a inteligibilidade do mundo ou dos enunciados fazendo da multiplicidade fenomênica uma unidade" (RUPRECHT, 1997, p. 59). Ele se dedicou mais especificamente a definir dois tipos de racionalidade, a racionalidade prática, que rege a coerência de nossos discursos cotidianos, mas também de discursos científicos e técnicos, e a racionalidade mítica, que rege a coerência e a forma particular de inteligibilidade dos discursos literários, e, de modo mais geral, estéticos, cujo objetivo não é nos informar sobre um estado de coisas, mas significar.

A racionalidade prática subordina o sentimento de inteligibilidade e de sentido à possibilidade de inscrever estas unidades discretas que são as grandezas figurativas e os conceitos em redes inferenciais por meio da aplicação recorrente de relações unilaterais de dependência que assumem a forma quer de inclusões espaciais ou lógicas, quer de encadeamentos de ordem temporal ou causal. Na perspectiva da racionalidade prática, um texto, verbal ou visual, fará sentido na medida em que suas propriedades discursivas permitam instalar redes de unidades discretas - configurações ou cenários figurativos, conjuntos conceituais ou cadeias argumentativas - que se conformam às sancionadas por um saber associativo socioletal ou idioletal. Inversamente, serão tidos por incoerentes ou ilegíveis os textos que bloqueiam, por exemplo não atendendo à busca de uma continuidade figurativa ou lógica, o reconhecimento de redes inferenciais constitutivas de um saber associativo compartilhado.

Funciona de outro modo a racionalidade mítica que é um produto da construção de relações estruturais (de pressuposição recíproca) cujos termos interrelacionados correspondem aos traços categoriais, de natureza figurativa, não figurativa (tensiva e modal) ou axiológica que constituem o investimento semântico das grandezas figurativas ou conceituais. Enquanto a racionalidade prática funciona apenas no nível das grandezas discretas, a racionalidade mítica as apreende apenas para elaborar as representações semânticas de que são o lugar. Longe de ser - como na perspectiva da racionalidade prática - "as unidades a articular segundo o verossímil, em função do saber associativo, [as grandezas discretas] funcionam [do ponto de vista da racionalidade mítica] como 
variáveis - lugares vazios munidos de uma identidade - nos quais vêm se inscrever, analítica ou sincreticamente, as posições de estruturas significantes (de natureza topológica, perceptiva, modal ou axiológica)" (RUPRECHT, 1997, p. 62).

Geninasca denomina molar a apreensão cujo nível de pertinência são as grandezas discretas, e semântica aquela cujo nível de pertinência são as "estruturas significantes", isto é, os investimentos categoriais que essas grandezas discretas permitem manipular. Vemos que a racionalidade mítica, ao mesmo tempo que pressupõe a apreensão molar, subordina a significação de um texto à possibilidade de atualizar uma apreensão semântica. Na perspectiva da racionalidade mítica, a significação de um enunciado discursivo não depende mais do respeito a axiomas do saber associativo compartilhado: ela procede inteiramente por operações atribuíveis a uma instância enunciativa que se apossa, articulando-as por meio de relações estruturais, de todas as representações semânticas que permitem construir grandezas figurativas e conceptuais instaladas em um enunciado discursivo dado.

Autônomas sem ser exclusivas, as racionalidades prática e mítica determinam condições de legibilidade diferentes e asseguram a produção e a apreensão de duas classes distintas de discursos. A racionalidade prática assegura a inteligibilidade de discursos cujas propriedades discursivas permitem o estabelecimento de redes inferenciais que respeitam os constrangimentos inerentes ao mundo do senso comum (ou a algum outro mundo possível que seja regido por relações de dependência unilateral). O seu exercício se torna, contudo, insuficiente quando se abordam discursos literários e, de modo mais geral, estéticos, cujas propriedades discursivas condicionam a aplicação da apreensão semântica e, em consequência, da estratégia de coerência definida pela racionalidade mítica. A racionalidade prática coincide com uma concepção referencial, e com um uso muitas vezes utilitário da língua. Os discursos dos quais ela assegura a inteligibilidade informam o mundo e tentam explicá-la. Os discursos que satisfazem as condições de inteligibilidade da racionalidade mítica significam o mundo e tentam entendê-lo. Se uns permitem aumentar nosso saber sobre o mundo, os outros nos oferecem a experiência vivida de um mundo ao mesmo tempo inteligível e significante.

De uma classe de discursos a outra, o papel das grandezas figurativas muda: no lugar de signos-referência em discursos cuja função é fazer referência a um mundo real ou fictício, elas constituem, nos discursos estéticos (mesmo quando só são convocados para criar uma ilusão de realidade), os instrumentos de uma forma de pensamento que explora as suas virtualidades semânticas. Não surpreende vê-los então entretendo relações inéditas, alheias às redes inferenciais registradas no saber enciclopédico que define o verossímil e o verdadeiro em um espaço sociocultural dado.

A reflexão de Geninasca sobre as diferentes racionalidades se inscreve na esteira dos trabalhos de Jean-Pierre Vernant e de Claude Lévi-Strauss. Vernant foi de fato, no campo francês, o primeiro a expor a ideia de uma multiplicidade de racionalidades. Em sua contribuição para uma publicação conjunta chamada Divination et rationalité 
[Adivinhação e racionalidade], se pergunta sobre "a natureza das operações intelectuais implicadas no desenvolvimento da consulta oracular", sobre "o tipo de racionalidade [que] se exprime no jogo de procedimentos divinatórios" (VERNANT, 1974, p. 9). Na mesma época, Lévi-Strauss (1962) propõe sua reflexão sobre as diferentes lógicas que operam no pensamento científico e no pensamento mítico: aquela procede por explicações sucessivas de fenômenos limitados ao passo que esta aspira a uma compreensão geral e completa do mundo, vivido como um conjunto significante. Vemos que as racionalidades prática e mítica de Geninasca são tributárias da reflexão de Lévi-Strauss. Testemunha-o, obviamente, o empréstimo do adjetivo qualificativo mítico para uma das racionalidades destacadas, mas sobretudo a natureza dos modos da instauração da inteligibilidade que Geninasca atribui a essas duas formas de pensamento. Tal como o pensamento científico em Lévi-Strauss, sua racionalidade prática vai das partes ao todo, de tal modo que os termos antecedem as relações que ela instaura entre eles. Inversamente, a racionalidade mítica, tal como o pensamento mítico de Lévi-Strauss, prioriza as relações em detrimento dos termos que articulam, indo assim de um todo postulado às partes.

\section{Do sentido ao sentido-para-o-sujeito}

A distinção entre dois tipos da racionalidade, prática e mítica, e o reconhecimento da relação que liga racionalidades e propriedades discursivas permite diferenciar duas competências discursivas, ou seja, dois modos de instaurar enunciados discursivos como objetos significantes. Quanto ao poder-dizer, isto é, a possibilidade de produzir discursos cuja inteligibilidade e sentido se situam em níveis distintos de pertinência, a descrição das racionalidades é uma condição necessária, mas não suficiente da elaboração de uma tipologia dos discursos. Para Geninasca, não basta produzir sentido em função dessa ou daquela estratégia de coerência; "é necessário ainda produzir um sentido correspondente ao fundamento do sentimento de identidade do eu, da realidade do mundo e, em consequência, um regime de correlação. A emergência do sentido põe necessariamente em jogo o crer de um sujeito" (RUPRECHT, 1985, p. 92). Geninasca (1981, pp. 94-101) entende por crer "o modo de inscrição de um sujeito [...] na dimensão do querer", ou ainda "o modo de pensar e viver a relação com a ordem dos valores". Cada ato de discurso apresenta-se, portanto, como a atualização de uma racionalidade que condiciona o poder dizer, e de um crer que determina o querer dizer: realizar um ato de discurso é ao mesmo tempo instaurar um enunciado discursivo como um objeto significante em função de uma estratégia de coerência, bem como assumir como verdadeiro (isto é, de acordo com uma relação com valores que determina o sentido-para-o-sujeito) o ato que produz a significação de um enunciado discursivo dado.

A tipologia de discursos pretendida por Geninasca é, assim, solidária de uma tipologia das competências enunciativas: cada classe de discurso - ou seja, cada Discurso 
(com maiúscula) - se define por uma competência discursiva, ou "racionalidade", e por uma competência e uma existência modais, ou "crer", atribuíveis a uma instância enunciativa dominante. Vai-se dizer de um dado discurso-ocorrência que ele pertence à classe do "Discurso estético" - ou religioso, científico, social etc. - para indicar sua conformidade com um tipo da racionalidade e de crer.

Mas tratar a questão da significação na perspectiva de uma multiplicidade de racionalidades, de apreensões do sentido e de creres, como o faz Geninasca, não pode deixar de pôr em dúvida pontos essenciais do edifício teórico da semiótica greimasiana, a começar pelo percurso gerativo e o quadrado semiótico, sobre cuja pertinência Greimas e Geninasca sempre discordaram.

\section{Discursivização versus instauração da significação}

O modelo do "percurso gerativo" elaborado por Greimas define os objetos semióticos segundo seu modo de produção, a construção da significação sendo concebida como um processo de enriquecimento progressivo "que vai do mais simples ao mais complexo, do mais abstrato ao mais concreto" (GENINASCA, 1993, pp. 41-57). Ele prevê, como se sabe, vários níveis de profundidade superpostos, que articula segundo um princípio ascendente, desde instâncias ab quo - as estruturas semionarrativas com as suas sintaxes e semânticas fundamentais e narrativas - até instâncias ad quem, as estruturas discursivas com seus componentes sintáticos (actorialização, temporalização, espacialização) e semânticos (tematização, figurativização) (GENINASCA, 1993, pp. 208-209). A ideia de percurso se impôs para vencer a distância entre as coerções lógico-semânticas da produção da significação e as articulações desses conjuntos significantes que são os discursos. A prioridade atribuída às estruturas profundas segue o primeiro postulado da semiótica greimasiana, que subordina toda produção da significação à existência de uma - e única - estrutura, ao mesmo tempo universal e elementar, cujo modelo é o quadrado semiótico. Apresentando o discurso como o resultado da "manipulação de formas profundas que acarreta um acréscimo de articulações significantes" (GENINASCA, 1993, p. 127), o percurso gerativo admite a existência de uma significação anterior à discursivização, sendo por outro lado indiferente às operações ligadas à textualização e à manifestação, que podem "intervir a qualquer momento do processo gerativo" (GENINASCA, 1993, p. 208), "Construção ideal, independente das línguas naturais (e anterior a elas) ou dos mundos naturais em que esta ou aquela semiótica pode a seguir investir-se para se manifestar" (GENINASCA, 1993, p. 208), o percurso gerativo situa-se inteiramente no plano do conteúdo. Espécie de semântica geral, ele, na verdade, gera menos a significação desse ou daquele discurso do que constrói o significado do enunciado discursivo, verbal ou não verbal, que seria sua manifestação. 
Sob a forma que recebeu em 1979, o percurso gerativo contribuiu durante uma dezena de anos para orientar a pesquisa semiótica. Se progressivamente deixou o primeiro plano para dar lugar à exploração dos diferentes níveis profundos que prevê, o percurso gerativo nunca deixou de ser o modelo de referência da semiótica greimasiana. A imagem de uma geração linear da significação, que vai se enriquecendo de um nível hierárquico para o outro, nunca foi questionada mas, ao contrário, reapareceu mais recentemente num último avatar, "o percurso gerativo da expressão" (FONTANILLE, 2008). Entretanto, ela traz muitos problemas, a começar pelo papel que atribui à enunciação.

Instância da discursivização, a enunciação é chamada, no modelo do percurso gerativo, a encarregar-se das estruturas semionarrativas do nível profundo e transformá-las em estruturas discursivas. Ao mesmo tempo que traz um acréscimo de articulações significantes, a "discursivização" - operação enunciativa na qual consiste essa transformação - apresenta-se, desse modo, como a atualização de uma significação já estruturada anteriormente. Geninasca, por seu turno, em vez de conceber o discurso como um conjunto significante anterior a qualquer manifestação e cuja existência depende de uma coerção estrutural ab quo de natureza lógico-semântica, postula que o discurso é o objeto semiótico que o ato enunciativo faz existir ao transformar um enunciado discursivo em um todo de significação, mediante a aplicação da ou das estratégias de coerência que esse enunciado permite.

A enunciação não se reduz, nessa perspectiva, à discursivização ou à convocação de uma significação preconstruída, mas corresponde ao ato de instauração da significação. Pôr em questão o percurso gerativo, não equivale, portanto, a abrir mão de uma concepção gerativa da significação. Todavia, as suas articulações discursivas não mais se situam ao final de uma série de conversões sucessivas entre níveis de profundidade organizados em uma hierarquia - conversões cujos procedimentos (sem os quais o percurso gerativo não pode ter caráter operatório), como se sabe, nunca se especificou - mas resultam da integração, atribuível a uma instância enunciativa, de uma multiplicidade de práticas discursivas entre as quais cada uma ativa uma apreensão do sentido, uma racionalidade e um crer.

\section{A hipótese de uma multiplicidade de estruturas}

Subordinar, como o faz Geninasca, a produção da significação à integração de uma multiplicidade de práticas discursivas que instauram, em diferentes níveis de pertinência, redes relacionais ou estruturas de natureza diferente, equivale a contestar o ponto de partida da semiótica greimasiana que consiste em postular um "modelo constitucional" único (o quadrado semiótico) que se supõe corresponder à estrutura elementar pressuposta por toda articulação da significação. As articulações discursivas não aparecem mais, a partir de então, como o lugar da discursivização de uma coerção estrutural definida de antemão, mas se tornam o lugar da produção mesma da significação - produção que dependerá 
ao mesmo tempo, indissociavelmente, da atividade de uma instância enunciativa e da escolha das variáveis que são as grandezas figurativas (actoriais, espaciais, temporais, "objectuais") ou conceituais.

Convém então fazer a distinção entre as condições de emergência do sentido e as operações enunciativas que governam a instauração da significação. É o que faz Geninasca em um artigo de 1981, em que ele propõe de dissociar a apreensão dos termos solidários de um eixo semântico e sua interpretação em termos lógicos tal como prevê o quadrado semiótico:

\begin{abstract}
A existência do eixo semântico é anterior à e independente da instauração das relações lógicas capazes de sobredeterminar a relação de pressuposição mútua (propriamente semântica) que funda a existência dos termos primitivos (GENINASCA, 1981, p. 29).
\end{abstract}

Enquanto condição da emergência do sentido, a apreensão das diferenças pertinentes sobre um fundo de semelhança é primeira. Sua interpretação lógica corresponde a um ato subsequente, atribuível à instância de enunciação que articula ou transforma as oposições semânticas no discurso pela e através da escolha de variáveis figurativas ou conceptuais. O tipo de articulação lógica das diferenças pertinentes não é mais então função dos próprios termos, mas depende da escolha da instância de enunciação, livre para instaurar entre eles uma relação de incompatibilidade (as relações de contrariedade e contradição previstas pelo quadrado semiótico) ou de compatibilidade (pensemos, por exemplo, nas figuras paradisíacas de que se servem mitos e textos literários para significar a totalização do sentido). Desse modo, embora condicionada pela apreensão de diferenças pertinentes, a produção da significação não é mais subordinada à existência de uma e só uma estrutura elementar: ela pressupõe ao contrário a existência de uma multiplicidade de estruturas que cabe a uma instância enunciativa integrar.

\title{
Variáveis e produção da significação
}

Pondo a significação dos discursos sob a dependência de uma atividade enunciativa que, seja qual for a estratégia de coerência que escolhe, manipula diferenças mediante variáveis figurativas ou conceptuais, Geninasca também se afasta de outra tese constitutiva do percurso gerativo, a que consiste em pensar o discurso como um todo de significação anterior a e independente de qualquer manifestação. Assim agindo, ele na verdade apenas tira as consequências teóricas de um texto que Greimas tinha dedicado, em 1973, às relações que ligam as estruturas semionarrativas às estruturas discursivas e os actantes aos atores. Em um artigo de 1985 (depois retomado em La Parole littéraire) sobre a figuratividade, e mais precisamente sobre o papel das grandezas figurativas na construção de enunciados discursivos como conjuntos significantes ou "discursos", Geninasca cita a conclusão desse texto de Greimas (1977, pp. 179-186): 
A estrutura actorial aparece assim como uma estrutura topológica: decorrente, ao mesmo tempo, de estruturas narrativas e de estruturas discursivas, ela é apenas o lugar de sua manifestação, não pertencendo propriamente nem a uma nem a outra. (GREIMAS, 1973, 185).

Com base na ideia de "estrutura topológica", Geninasca desenvolve o conceito de variável:

Se designamos por A a "estrutura topológica" e por $x$ e $y$ as classes de investimentos necessários e suficientes para determinar a existência de um ator, este responderá a fórmula $\mathrm{A}(x ; y)$. Os valores de $x$ e de $y$ podem variar no decorrer da narrativa, sem por isso comprometer a identidade da variável, indicada por A.

O conceito de variável actorial, mas também objetual, espacial ou temporal permite explicar a permanência de um ator, ou mesmo de toda grandeza figurativa, em um enunciado discursivo, apesar das mudanças que afetam os investimentos ou as representações de que ele é o lugar de manifestação. Mas o mesmo conceito faz aparecer também uma dificuldade teórica do percurso gerativo, na medida em que essas variáveis - ou "estruturas topológicas", para falar com Greimas -, cuja função é conjugar "estruturas narrativas" e "estruturas discursivas", ou seja, representações que dependem de dois níveis distintos do percurso gerativo, não podem, por definição, pertencer elas mesmas ao mesmo percurso. Além disso, elas não são identificáveis, segundo Geninasca, "nem com as estruturas significantes [...] necessárias à compreensão dos enunciados, nem com os formantes (lexemas, expressões fixadas da língua ou figuras, configurações do mundo natural) nem tampouco com os segmentos da cadeia verbal que asseguram a sua instalação" (GREIMAS, 1983, p. 7). Trata-se de grandezas discursivas no sentido de que elas "só têm realidade por meio da e para a instância enunciativa que as põe e, pondo-as, Ihes confere a existência precária de objetos mentais" (GREIMAS, 1983, p. 7).

Uma das consequências da introdução do conceito de variável — mas Greimas não o tinha pressentido desde 1973? — é que não se pode pensar o discurso como um todo de significação situado inteiramente no plano do conteúdo e anterior a toda manifestação. A significação de um discurso só tem existência pela e através da fala que a instala. Ela reside nas operações enunciativas que conjugam uma estratégia de coerência e certas virtualidades discursivas, de natureza semântica, que permitem manipular e transformar essas variáveis actoriais, objetuais, espaciais ou temporais cuja instalação em um enunciado discursivo está subordinado à atualização de um formante, no sentido hjelmsleviano do termo, do plano de expressão de uma semiótica dada. Nessa perspectiva, o discurso não é o resultado de uma semiose entendida como a colocação numa relação de pressuposição mútua de uma forma de conteúdo e uma forma da expressão. Ele só tem existência quando atualizado, assumido por uma instância de enunciação. 


\section{O discurso, lugar de atualização e de elaboração da significação}

O conceito de variável concebido por Geninasca permite por outro lado compreender melhor o papel do discurso na articulação e reformulação de formas culturais fixadas pelo uso. Instalar uma grandeza figurativa ou conceptual em um enunciado discursivo equivale a instaurar uma variável com o estatuto de totalidade discreta e, ao mesmo tempo, a atualizar algumas estruturas significantes cristalizadas - cenários e configurações registrados no saber associativo de um espaço sociocultural dado - de que a instância de enunciação não poderia prescindir, seja qual for o uso, utilitário ou poético, que faça da fala. Sem sua contribuição, as variáveis permaneceriam lugares vazios, destituídos de qualquer determinação. Inversamente, os cenários e configurações consagrados pelo uso estão, por meio das variáveis que os atualizam, à disposição da instância de enunciação que os articula, os combina e os transforma para criar significações ainda inéditas. Visto assim, o discurso se mostra tanto como um lugar de criação, quanto como o resultado de uma bricolagem, no sentido de Lévi-Strauss, que reutiliza "resíduos de discursos precedentes", para retomar a expressão de Geninasca.

A concepção do discurso como o lugar da atualização e da transformação de entidades preconstruídas, mas também como o lugar da produção de novas significações, ou mesmo da elaboração de futuras formas fixadas do sentido não deixa de lembrar a orientação da semiótica greimasiana, nos anos 1990, sob o impulso de D. Bertrand, J. Fontanille e Cl. Zilberberg, rumo a uma concepção de enunciação que articula as formas discursivas da enunciação individual sobre as organizações significantes sedimentadas pelo uso, em outras palavras, engendradas pela "práxis enunciativa" ${ }^{3}$. Todavia, ao examinar as pesquisas que giram em torno do que Bertrand (1999, p. 25-32) chama de "o impessoal da enunciação", apesar delas concentrarem a atenção nas "formas discursivas que o uso das comunidades socioculturais fixa na forma de tipos, de estereótipos ou de esquemas" (BERTRAND, 1999, p. 25), elas continuam a pensar a enunciação como a convocação de uma significação cujas articulações se situam inteiramente no plano do conteúdo e que são supostamente independentes da textualização e da manifestação. Os mecanismos de convocação são pensados, com efeito, como regendo um duplo registro estrutural:

De um lado, incidem sobre universais (semionarrativos e modais, por exemplo), e, do outro, sobre as formações legadas pelo uso, que, por um retorno do discurso sobre si mesmo, se instalam no centro do nível semionarrativo e aí se configuram como primitivos convocáveis. Esses módulos estruturais, filtros de nossas leituras e de nossas produções de sentido, fixam-se no esquema no qual se apresentam como taxionomias sintagmáticas (BERTRAND, 1999, p. 31).

3 Ver uma apresentação concisa em Bertrand (1993). 
Quer a instância de enunciação convoque "universais" ou "primitivos", permanece o fato de que seu papel se restringe a atualizar uma significação previamente estruturada, posta na dependência das estruturas semionarrativas.

A possibilidade de se ater a uma concepção da enunciação como simples atualização de uma significação anterior à manifestação se explica pelo estatuto ideal que a semiótica greimasiana atribui às formações legadas pelo uso. Se correspondem no início a enunciações anteriores que nos chegam na forma de frases fixadas, estereótipos figurativos ou fraseologias, supõe-se que essas formações do uso se transformem, sob a ação da práxis enunciativa, em "taxionomias sintagmáticas", em outras palavras, em articulações apenas do plano do conteúdo. A sua transformação em "primitivos convocáveis" vai de mãos dadas com a perda da sua natureza de resíduos de discursos prévios. Isso é o custo teórico da integração da práxis enunciativa numa concepção da enunciação que seja possível articular com o modelo do percurso gerativo da significação, que prioriza as instâncias ab quo da ordem lógico-semântica. Em seu princípio, essa concepção da enunciação vai ser muito pouco questionada nos trabalhos subsequentes da semiótica greimasiana, embora eles a enriqueceram, notadamente ao reconfigurar a enunciação como "prática" no âmbito daquilo que Landowski (2004, pp. 15-18, 106-108; FONTANILLE, 2008) chama "situações semióticas". É como se a evolução da semiótica greimasiana sempre fosse só uma busca de aprimoramento e como se os acréscimos e enriquecimentos nunca devessem afetar a integridade de conceitos-chaves como o percurso gerativo e o quadrado semiótico, que parecem ter sido absolutamente intangíveis - apesar das brechas abertas no edifício teórico, a começar pelo próprio de Greimas.

\section{A organização discursiva sui generis dos discursos estéticos}

Convencido de que a eficácia analítica é um dos principais critérios de avaliação de teorias, Geninasca se dedicava continuamente a aprimorar procedimentos de análise destinados a constituir em objetos semióticos os textos literários e os quadros de que se ocupava. Expondo-se sem cessar ao risco da leitura, concebia a construção de uma teoria semiótica do discurso como um constante ir e vir entre o desenvolvimento de modelos gerais, necessariamente provisórios, e uma prática de análise, que, instaurando um dado discurso-ocorrência em um todo de significação, corresponde por outro lado a uma crítica ativa aos modelos que a orientam. Entre os modelos gerais desenvolvidos, aquele da organização discursiva cuja atualização condiciona a construção da significação dos discursos-ocorrências de vocação estética (em outras palavras, aqueles que remetem à "racionalidade mítica") ocupa um papel central, na medida em que articula estruturas manifestas e estruturas imanentes (GENINASCA, 1997, 81-106) ${ }^{4}$.

Esse modelo de organização discursiva leva ao reconhecimento, em um objeto textual dado, verbal ou não verbal, de uma hierarquia de espaços textuais parciais cuja

4 Esse modelo passou por vários desenvolvimentos em diversos trabalhos de Geninasca (1997). 
instauração resulta de uma sequência organizada de divisões do espaço textual global em lugares formalmente indexados por signos demarcadores. Segundo a natureza do objeto textual considerado - obra literária, pintura, escultura, fotografia, construção arquitetônica etc. - a natureza dos signos demarcadores varia. A repetição de um lexema, de uma grandeza figurativa ou de uma configuração perceptiva, a ocorrência de um paralelismo fônico, figurativo ou plástico (eidético, cromático ou luminoso), ou ainda a mudança da modalidade enunciativa são alguns entre os processos que podem atuar como sinais demarcadores. A originalidade e o interesse desse modelo do discurso estético reside na correlação estrita que estabelece entre os espaços textuais delimitados e os espaços semânticos ou unidades discursivas correlacionadas. A cada relação paradigmática, sintagmática e hierárquica reconhecida entre os espaços textuais corresponderá uma relação semântica da mesma natureza entre as unidades discursivas e as representações semânticas que veiculam. Em outras palavras, os pares de unidades discursivas do mesmo nível hierárquico ligam-se por uma dupla relação da equivalência e de transformação semântica. A atualização da organização discursiva determina assim uma hierarquia de transformações semânticas que, atribuíveis a uma instância de enunciação, são outros tantos atos enunciativos. Construir a significação de um objeto estético dotado dessa organização discursiva equivale a realizar a hierarquia dos atos enunciativos de que ela é a marca objetivada, observável no plano fenomênico.

Concebido como uma forma semiótica independente das significações particulares que se supõe receber, esse modelo do discurso estético parece ter uma grande generalidade. Seu caráter operacional foi testado na análise de textos literários, em verso e prosa, de épocas e línguas diferentes, bem como no campo de pintura, da escultura, do filme e da fotografia ${ }^{5}$. Sua adequação vem do fato de se basear em operações isomórficas àquelas mobilizadas pela racionalidade mítica. Instala de fato, entre as unidades discursivas coextensivas a espaços textuais que resultam da divisão organizada de um espaço textual global, as mesmas relações da pressuposição mútua que a racionalidade mítica estabelece entre os investimentos semânticos das variáveis de uma linguagem dada (grandezas figurativas, conceitos, gestos etc.). Tanto o modelo da organização discursiva como a racionalidade mítica subordinam assim a inteligibilidade e o sentido à construção de relações estruturais que eles investem de um valor fundador em relação com os termos que articulam.

Tal como a conceitualização da racionalidade mítica, o modelo do discurso estético oferecido por Geninasca é tributário da reflexão de Lévi-Strauss sobre os mitos. Segundo o antropólogo, a estrutura dos mitos equivale a um percurso que leva de uma situação inicial que organiza conteúdos invertidos (por exemplo, um estado da falta resultante da violação de um contrato) a uma situação final que atualiza um conteúdo posto, que muitas vezes toma a forma do restabelecimento do contrato, ou da invenção de um objeto

5 Cf. em primeiro lugar os trabalhos de Geninasca (1997); /sobre tela "La Perspective amoureuse ou les métamorphoses du regard" de René Magritte (1936); Bähler (1997); Bernet (1999); Schulz (2004); Thut (1989); Vogel (1993); Fröhlicher, Güntert, Thürlemann (1990); Burkhardt, Plattner, Schorderet (2009). 
cultural. Do mesmo modo, o modelo da organização discursiva de Geninasca, em sua manifestação mais elementar, articula dois espaços textuais, inicial e final, resultantes da divisão de um espaço textual global, e coextensivos a duas unidades discursivas de conteúdos solidários, invertido e posto. De fato, muitos textos literários e obras de arte se apresentam como percursos de conversão organizados para fazer passar o leitor de uma racionalidade e de um crer enganosos à posição enunciativa de um Discurso poético que se supõe dar o sentimento mais intenso da identidade do sujeito e da realidade do mundo.

Essa armadura elementar não deixa de lembrar aquela da narrativa mítica, que Greimas, também com base em trabalhos de Lévi-Strauss, desenvolveu em seu ensaio "Para uma teoria de interpretação da narrativa mítica" (GREIMAS, 1975, pp. 171-216). Diferencia-se, contudo, fundamentalmente, tanto por seu alcance como por sua natureza e sua eficácia interpretativa. Pelo seu alcance, em primeiro lugar, porque é independente de qualquer conteúdo particular e, portanto, capaz de informar todo objeto textual, verbal ou não verbal, que dependa da racionalidade mítica, enquanto a armadura da narrativa mítica desenvolvida por Greimas é um modelo narrativo que aponta especificamente para uma "subclasse de relatos (mitos, contos, peças de teatro, etc.)", definida "por uma propriedade estrutural comum, a dimensão temporal" que faz com que "os comportamentos que ali estão repartidos entretêm entre eles relações de anterioridade e de posteridade (GREIMAS, 1975, p. 173). E também por sua natureza, porque estabelece uma correspondência termo a termo entre, de um lado, os espaços textuais, e, de outro, as unidades discursivas, e, portanto, entre os planos da expressão e do conteúdo, o que vincula a organização discursiva de Geninasca ao grupo das semióticas semi-simbólicas. A armadura do relato mítico de Greimas está, ao contrário, apenas no plano do conteúdo: correlacionando a articulação da dimensão temporal do mito segundo um antes e um depois, com "uma reversão da situação", (GREIMAS, 1975, p. 173). isto é, com a passagem de um conteúdo invertido a um conteúdo posto, ela é independente das estruturas manifestas.

Com isso, o modelo do discurso estético e a armadura do relato mítico condicionam procedimentos de análise que se destacam por sua eficácia interpretativa. Por causa da correlação estrita que estabelece entre os espaços textuais, delimitados com a ajuda de procedimentos observáveis, como pares e paralelismos de diversas naturezas, e as unidades discursivas, o modelo de Geninasca assegura a seleção e permite a construção de representações semânticas pertinentes para instaurar um dado discurso-ocorrência em um todo de significação. Ao contrário do modelo de Geninasca, a armadura da narrativa mítica não regula a passagem das estruturas manifestas às estruturas imanentes. A segmentação de um mito dado em sequências, que a armadura de Greimas prevê, não se efetua em função de procedimentos textuais, mas resulta da projeção das articulações de conteúdo previstas pelo modelo de referência, segundo o qual as sequências destacadas "correspondem às articulações previsíveis dos conteúdos" (GREIMAS, 1975, p. 174). O recorte tem, assim, apenas um valor heurístico: permite identificar, "com a ajuda de uma 
transcrição normalizada, os elementos e sintagmas míticos" contidos em uma sequência dada (GREIMAS, 1975, p. 174). A armadura da narrativa mítica pode em consequência servir de modelo de previsibilidade apenas para uma prática interpretativa de natureza projetiva, que concebe um mito-ocorrência como uma atualização de conteúdos previamente estruturados. É diferente com o modelo do discurso estético de Geninasca, pois permite estabelecer espaços textuais que entretêm relações de equivalência e transformação semânticas. A organização discursiva, portanto, não mais reflete articulações de conteúdo previstos por uma estrutura anterior, mas condiciona a atualização, por uma instância enunciativa, de um conjunto de transformações semânticas que instaura uma significação inédita.

Destaquemos para concluir a natureza toda relacional do modelo da organização discursiva de Geninasca. Resultado de operações que conjugam certas propriedades dos objetos textuais e as expectativas de um sujeito que emprega uma estratégia de coerência explorando os recursos da racionalidade mítica, não está inteiramente nem no objeto textual nem no sujeito. Sua atualização coincide com a instauração do sujeito da enunciação implícita, que assume a hierarquia das transformações semânticas que ele define. Distinto do autor e dos leitores empíricos (que na verdade podem assumir, sob condições diferentes, os mesmos papéis e posições), o sujeito da enunciação implícita também é distinto de instâncias enunciativas enunciadas, inscritas nos textos. Se estas se encarregam das representações semânticas ligadas aos espaços textuais parciais, tomados separadamente, o sujeito da enunciação implícita se encarrega da significação global resultante da atualização da hierarquia dos atos enunciativos definidos pela organização discursiva em seu conjunto. Esse sujeito corresponde, em última análise, à competência discursiva pressuposta pela constituição de um objeto estético em um todo de significação.

O isomorfismo que o modelo do discurso estético postula entre as estruturas discursivas e as configurações subjetivas permite, entre outras coisas, compreender em que consiste a significação de objetos estéticos, verbais e não verbais, que são passíveis de uma apreensão "impressiva" cujo nível de pertinência se define por sua relação com as configurações perceptivas, de ordem fônica, cromática, eidética ou luminosa, que ela correlaciona com os estados tensivos e modais do sujeito. Tomada em carga pela organização discursiva, a variação das configurações perceptivas e dos estados do sujeito é interpretável em termos de diferenças pertinentes, de modo tal que a passagem de uma configuração perceptiva a outra seja vivida, pela instância enunciativa que a assume, como uma transformação de ordem somático-patêmica. Construir como discurso um objeto estético passível de uma apreensão impressiva equivale, nesta perspectiva, a instaurá-lo como um todo de significação sensível, assegurando uma forma de conhecimento do mundo vivido como experiência somático-patêmica. 


\section{Novas perspectivas semióticas}

Um dos principais méritos da semiótica de Geninasca é sem dúvida ter garantido a seus conceitos e modelos constitutivos um estatuto operatório por meio do desenvolvimento de procedimentos de análise que regulam a passagem das estruturas manifestas às estruturas imanentes. Pode assim constituir em objetos empíricos os discursos-ocorrência - textos literários e obras de arte - que aborda. Uma teoria semiótica do discurso de fato não poderia reduzir o discurso, ao contrário do percurso gerativo, a uma grandeza situada inteiramente no plano do conteúdo, anterior à e independente da textualização e da manifestação. Reduzir o papel das operações de textualização e de manifestação à presentificação de conteúdos estruturados de antemão equivaleria a negar qualquer função semântica às escolhas estilísticas e, de modo mais geral, estéticas. Por essa razão, Geninasca incansavelmente lembrava que os pintores e escritores raciocinam com a ponta do pincel ou da caneta, enfatizando assim o peso do sensível na elaboração da significação.

Fazendo a distinção entre as condições de emergência do sentido e as coerções discursivas que determinam a produção e a apreensão da significação, a semiótica de Geninasca define-se por sua relação com um novo conjunto de questões. O problema das conversões entre níveis de profundidade, cuja elaboração seria a única base da validade do percurso gerativo da significação, é substituído pela questão da integração, atribuível a uma instância de enunciação, de uma multiplicidade de linguagens, de apreensões e de racionalidades. Por outro lado, pondo a coerência e a inteligibilidade dos discursos não sob a depêndencia de uma estrutura elementar anterior à atividade enunciativa mas, ao contrário, sob a égide de uma instância de enunciação que conjuga estratégias de coerência e morfologias textuais, Geninasca anula a oposição entre semiótica "objetal" e semiótica "subjetal", em benefício de uma teoria semiótica geral do discurso.

A existência de procedimentos de análise que permitem ir de um objeto estético à competência enunciativa que rege sua instauração como conjunto significante também abre novas perspectivas para a teoria e a prática de análise do discurso literário, e, de modo mais geral, estético. Desse modo, um estudo comparado das competências enunciativas construídas a partir de análises de obras de escritores diferentes permitiu renovar a história literária na direção de uma história das poéticas, sendo cada poética entendida como a competência enunciativa específica que governa um conjunto de obras remetendo a um Discurso poético dado, caracterizado por um modo particular de articular apreensões, racionalidades e creres para fundar um modo de pensar o sentido do mundo e a identidade do sujeito. Nesse contexto, cabe um papel decisivo ao estudo do dialogismo intratextual, isto é, da posição, frequentemente encenada nos textos literários, que o Discurso poético se atribui em relação aos outros Discursos, especialmente sociais, religiosos, filosóficos e científicos, com os quais compartilha o campo sociocultural de uma época. 
Apoiar-se em um conjunto de modelos e conceitos interdefinidos - modelo de organização discursiva, conceitos de apreensão molar, semântica e impressiva, racionalidades inferencial e mítica, crer, o princípio do dialogismo etc. - que se supõe definir as condições invariáveis da construção dos discursos literários, permite também, com efeito, descobrir os elementos que variam de uma poética a outra no decorrer do tempo. Caberia especificar, por exemplo, o uso que uma dada poética faz das grandezas figurativas. Assim, será que as redes de figuras instaladas nos textos respeitam configurações e percursos figurativos registrados no saber associativo vigente em um espaço sociocultural dado, para, por exemplo, criar um efeito de real? Ou, ao contrário, eles bloqueiam qualquer leitura referencial para fazer o leitor atualizar uma estratégia de coerência que envolve uma apreensão impressiva e uma apreensão semântica, subordinando por meio disso a inteligibilidade e o sentido à possibilidade de instaurar relações de equivalência e transformação entre os investimentos categoriais das grandezas figurativas convocadas? Também seria necessário analisar os diferentes modos de pensar a relação do sujeito com a ordem dos valores: não é a mesma coisa propor uma ontologia de valores que funda o sentido de nosso ser no mundo ou, ao contrário, negar a sua existência mantendo, porém, a exigência de uma relação tensiva com a ordem dos valores, vivida como sentido. Para além da simples classificação cronológica dos autores, uma história das poéticas fundada no dialogismo intratextual das racionalidades e dos creres permitiria descrever a variação histórica dos meios e das operações explorados pelos discursos literários para construir a imagem de sua ancoragem em um campo dialógico dado. Ela seria ao mesmo tempo uma história de estilos e de escritas e uma história dos confrontos entre diferentes relações com a ordem dos valores e dos modos de instauração do sentido.

Independentemente das significações particulares e da natureza das formas manifestas que articula, o modelo do discurso estético de Geninasca abre finalmente a possibilidade de um comparatismo generalizado, na medida em que permite comparar os resultados de análises de objetos estéticos de natureza diferente, textos literários, quadros, esculturas, fotografias ou filmes, para evocar apenas algumas práticas artísticas que dependem da racionalidade mítica. Vemos assim como a semiótica de Geninasca poderia contribuir para renovar o diálogo entre pesquisadores do campo das letras, historiadores da arte e, por exemplo, também especialistas em cinema, inspirando projetos de pesquisa interdisciplinar, realizados no quadro de uma teoria das linguagens, das apreensões do sentido, das racionalidades e dos creres.

O avanço da semiótica de Geninasca foi pontuado desde o começo por um questionamento crítico a respeito das pesquisas e dos trabalhos de Greimas. Ainda que quase chegando a desconstruir os modelos emblemáticos do quadrado semiótico e do percurso gerativo, por definição hipotéticos e provisórios, Geninasca nunca deixou de contribuir para que a semiótica permaneça um "projeto com vocação científica" que está sempre para 
recomeçar. "Será justo, e puro, o gesto que permita continuar inventando", ${ }^{6}$ escreveu Greimas na conclusão de uma "carta inhabitual", depois da publicação de Da Imperfeição. Por isso, não surpreende que seus próprios trabalhos, dedicados à instauração dos mais diversos objetos estéticos enquanto conjuntos significantes, e a uma grande variedade de questões teóricas, sejam lidos, por sua vez, como outros tantos convites - e provocações - à pesquisa.

Traduzido do francês por Adail Sobral e Ana Claudia de Oliveira.

Michael Schulz é consultor de mercado senior, atua na MetaDesign, Genebra. Graduado em linguística e literatura (francês e italiano) e graduado em História da Arte. Doutor em Literatura Francesa. Colaborador de Jacques Geninasca na Universidade de Zürich. Seus interesses voltam-se à semiótica literária, semiótica da fotografia e do audiovisual e semiótica da arte, semiótica do branding e da comunicação.

mschulz@metadesign.ch

\section{Referências}

BÄHLER, U. Pour lire Joë Bousquet. Approches sémiotiques de La Connaissance du Soir. Paris: L'Harmattan, 1997.

BERNET, T. L'Ironie d'Alberto Savinio à la croisée des discours. Lecture sémiotique de l'Introduction à une vie de Mercure et d'Achille énamouré mêlé à l'Evergète. Berne: Peter Lang, 1999.

BERTRAND, D. L'impersonnel de l'énonciation. Praxis énonciative: conversion, convocation, usage. Protée, XXI, 1, 199.

FONTANILLE, J. Pratiques sémiotiques. Paris: PUF, 2008.

GENINASCA, J. Note per un'analisi strutturale del primo canto della Divina Commedia. Problemi, 13, 1969.

. Analyse structurale des Chimères de Nerval. Neuchâtel: La Baconnière, 1971.

.Solidarité vs (compatibilité ou incompatibilité): Actes sémiotiques. Bulletin, IV, 17, 1981.

L'identité intra- et intertextuelle des grandeurs figuratives. In: PARRET, H.; et RUPRECHT,

H. G. (Eds.). Exigences et perspectives de la sémiotique. Recueil d'hommages pour A. J. Greimas. Amsterdam: Benjamins, 1985 (rééd. sous le titre "Sur le statut des grandeurs figuratives et des variables »dans La Parole littéraire).

. La Perspective amoureuse ou les métamorphoses du regard. Cruzeiro Semiótico, 9, 1988.

. Lettre à A. J. Greimas, Zurich, le 8 mars 1988. In: A la mémoire de Jacques Geninasca: Actes Sémiotiques, 115, 212. Disponível em: http://epublications.unilim.fr/revues/as/731

Les acquis et les projets. Hommages à A. J. Greimas. Nouveaux Actes Sémiotiques, 25, 1993.

La Parole littéraire. Paris: PUF, 1997.

6 Carta de Geninasca a Greimas, Zurich, 8 de março de 1988. Cf. A la mémoire de Jacques Geninasca, Actes Sémiotiques, 115, 212. Disponível http://epublications.unilim.fr/revues/as/731 
. Et maintenant? In: LANDOWSKI, E. (Ed.). Lire Greimas. Limoges: Presses Universitaires de Limoges, 1997.

GREIMAS, A. J. Pour une théorie de l'interprétation du récit mythique. Communication, 8, 1966 (rééd. in A. J. Greimas. Du Sens. Paris: Seuil, 1970).

Les actants, les acteurs et les figures. In: $\mathrm{CHABROL}, \mathrm{Cl}$.; COQUET, J.-Cl. (Eds.). Sémiotique narrative et textuelle. Paris: Larousse, 1973 (rééd. in A.J. Greimas, Du Sens II, Paris, Seuil, 1983).

— et COURTÉS, J. Sémiotique. Dictionnaire raisonné de la théorie du langage. Paris: Hachette, 1979.

LANDOWSKI, E. Passions sans nom. Textes et pratiques. Paris: PUF, 2004.

. Com Greimas, São Paulo: Estação das Letras e Cores, 2017.

LEVI-STRAUSS, C. La Pensée sauvage. Paris: Plon, 1962.

Myth and Meaning. New York: Schocken Books, 1979.

SCHULZ, M. Les espaces du regard. Notes sur le film Der Himmel über Berlin (Les Ailes du désir) de Wim Wenders. In: FRÖHLICHER, P.; GÜNTERT, G.; THÜRLEMANN, F. (Eds.). Espaces du texte. Spazi testuali - Texträum (Recueil d'hommages pour Jacques Geninasca). Neuchâtel: La Baconnière, 1990.

. Enonciation et discours esthétique. Analyser le Serial Project n 1 (Set A) de Sol LeWitt. In:

La Praxis énonciative: Nouveaux Actes Sémiotiques, 41-42, 1995.

. CHAR, R. Du texte au discours. Trois lectures sémiotiques. Paris: L'Harmattan, 2004.

. Le temps d'un regard. Les Américains de Robert Frank. In: BURKHARDT, M.; PLATTNER, A.; SCHORDERET, A. (Eds.). Parallelismen - Parallélismes - Paralelismos (Mélanges de littérature et d'analyse culturelle offerts à Peter Fröhlicher), Tübingen: Gunter Narr, 2009.

THUT, M. Le Simulacre de l'énonciation (Stratégies persuasives dans Les Chants de Maldoror de Lautréamont). Berne: Peter Lang, 1989.

VERNANT, J.-P. Paroles et signes muets. In: VERNANT, J.-P. et al. (Eds.). Divination et rationalité. Paris: Seuil, 1974.

VOGEL, C. Diderot: I'esthétique des Salons. Berne: Peter Lang, 1993.

Texto recebido em 20/08/2019

e aprovado em 19/10/2019. 